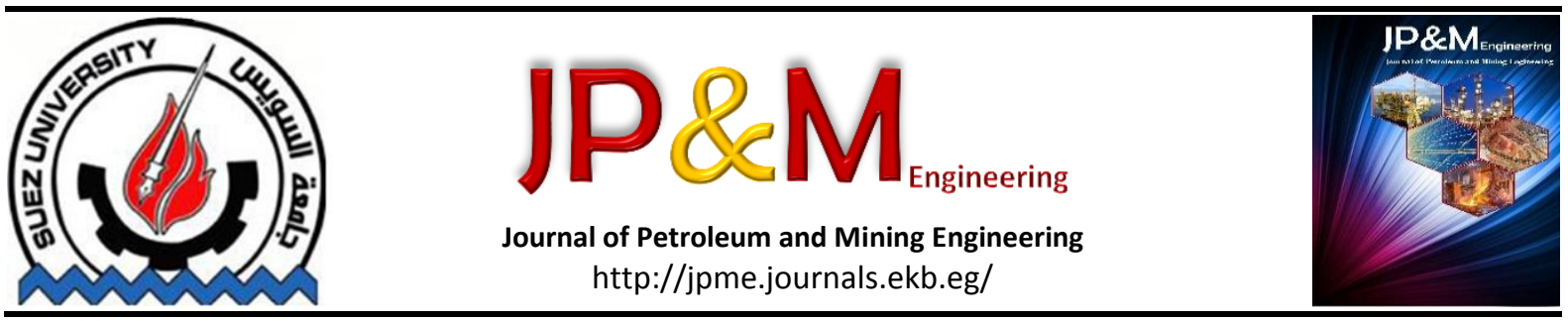

\title{
Effect of ASP Chemical Flooding Efficiency On Displacement Factor and Water Percentage After Exhaustion of Water Flooding Efficiency in DERO Field
}

\author{
Mosab B.A Albredi ${ }^{a}$ \\ Alfurat University- Faculty Of Petrochemical Engineering - Syria
}

\begin{abstract}
In this research a laboratory study of ASP flooding process followed by polymer solution (for mobility control) were performed in industrial core consist of marble, physical simulated the reservoir properties of productive Jreebi formation in DERO field. From my precedent studies: I found the types and optimum concentrations of ASP components that achieve maximum efficiency at minimum concentration (minimum interfacial tension for surfactant and alkaline - maximum viscosity for polymer). these types and optimum concentrations is $\mathrm{NaOH} 0.7 \% w t$, DDBSCa

\section{Keywords}

ASP Flooding; Sweep Efficiency ; Oil Recovery Factor Water flooded ; Displacement (Wetconat1220EH) $0.05 \%$ wt and Xanthan Gum 550 PPM. ASP flooding processes were performed by the following volumetric ratios: $15-30-50 \% \mathrm{PV}$ followed by $15 \%$ $\mathrm{PV}$ of polymer solution (for mobility control). Finally displacement liquid were injected up to $250 \% \mathrm{PV}$. All ASP flooding processes were performed in the formation conditions of DERO field.
\end{abstract}

Results of the laboratory study referred to increasing of oil producing and decline of produced water at all ratios of ASP solution.

\section{Introduction}

Surfactants, alkaline and polymers are the main components which are used in chemical enhanced oil recovery. The reaction between these chemicals greatly affect the final results of field experiments as they become mixed in the reservoir. [1]

. Thus, its preferred to inject these chemicals together (ASP) flooding in order to shorten the injection period and make the project economically feasible.[2] Nowadays, ASP is considered an attractive chemical enhanced oil recovery technique, since it combines the virtues of the three methods : alkaline, polymer and surfactant. As result, the high cost of surfactant is reduced by using alkaline in combination with surfactant and favorable mobility ratio is achieved by taking advantage of using polymer.[3]-[4]

There are more than 27 projects of chemical injection (ASP) distributed in Alberta fields, California, china, Colorado Indonesia, Louisiana, Oklahoma, Venezuela and Waummeng .[5]

In addition, there are 15 projects have been accredited for ASP in different fields of the world in 2008. And now, there are 12 projects for ASP to be developed in USA.[6]

\section{The purpose of this research:}

This research aim to Improve the displacement efficiency in DERO field and reduce water cut in productive wells by using ASP flooding after exhaustion of water flooding efficiency that applied in the mentioned field now.

Water injection started in DERO field through well 101 in 1993 and continued with low rates of $\left(30 \mathrm{~m}^{3} /\right.$ day) until 1996 where injection took place through 3 wells (101- 102-103) with daily rate of $\left(100 \mathrm{~m}^{3} /\right.$ day) while, the number of injection wells increased to 4 wells after converting well 8 to injector and in 1999 the daily injection rate increased to) $300 \mathrm{~m}^{3} /$ day) after drilling well 104 .

A study was carried out to determine the possibility of increasing the daily rate to $\left(500 \mathrm{~m}^{3} /\right.$ day) in the future. In addition, well 32 is equipped to inject the separated water in the treatment plant which began in 2005 .

As a result, the yearly injected water is $\left(77752 \mathrm{~m}^{3} /\right.$ day), cumulative water injected $\left(658857 \mathrm{~m}^{3} /\right.$ day $)$ versus cumulative fluid production (10703.106m3). This represent a small percentage of $38.5 \%$.

The screening criteria for ASP technique compared to the characteristics of DERO field are summarized in the following table: 
Table 1: The screening criteria for ASP technique compared to the characteristics of DERO field

\begin{tabular}{|c|c|c|}
\hline Index & $\begin{array}{c}\text { Reservoir } \\
\text { characteristic } \\
\text { In DERO field }\end{array}$ & $\begin{array}{c}\text { Screening } \\
\text { criteria }\end{array}$ \\
\hline API & $0^{35.1}$ & $>{ }^{\circ} 20$ \\
\hline $\begin{array}{c}\text { Formation } \\
\text { Viscosity (C.P) }\end{array}$ & 4.5 & $<35$ \\
\hline Oil Saturation (\%) & 65 & $>35$ \\
\hline $\begin{array}{c}\text { Permeability } \\
\text { (m.D) }\end{array}$ & 89.6 & $>2700$ \\
\hline Depth (m) & 600 & $>93$ \\
\hline $\begin{array}{c}\text { Formation } \\
\left.\text { Temperature (C }{ }^{\circ}\right)\end{array}$ & 33 & Not Critical \\
\hline Net Thickness (m) & 4.5 & $\begin{array}{c}\text { Sandstone } \\
\text { /carbonate }\end{array}$ \\
\hline $\begin{array}{c}\text { Type Of } \\
\text { formation }\end{array}$ & Carbonate & \\
\hline
\end{tabular}

After comparing the screening criteria and characteristics, a perfect match was observed which supported the possibility of using ASP in this field and improve the sweep efficiency.

ASP is considered easy to apply, since it does not require many surface facilities as $\mathrm{CO}_{2}$, steam injection and others. In addition, its safe and can be applied in different stages of field life.

In addition, the average $\mathrm{PH}$ of DERO field ranges about 8.5, which is considered very suitable for injecting surfactants, where losses due to both adsorption and precipitation will decrease. In turn it will become more effective. Also, alkaline is suitable to maintain the viscosity of aqueous polymers added to ASP.

\section{Literature Review :}

Son Wanchao proved that both viscosity and surface tension (oil/ASP) are the main factors affecting the production of oil using ASP. It was also, proved that carboxylic soap resulting from the reaction between alkali and organic acid in oil resulted in minimum surface tension at low concentration of the surfactant added to the injection solution, while the alkaline reduced losses of the surfactant. [7]

WeiWang \& Youngan $\mathrm{Gu}$ showed that the polymer, surfactant $\&$ alkaline concentration remains relatively high in the fluids produced in case of applying ASP injection method. Thus, ASP can have reduced the cost of the operation, and any loss is due to the adsorption or chemical reaction with the oil. [8]

According to Huabin\& Shutang, the daily production rate of oil increased from $36.7 \mathrm{~m} 3 /$ day to $91.5 \mathrm{~m} 3 /$ day during a pilot test using ASP in Daqig field, while the water cut decrease from $82.7 \%$ to $59.7 \%$. in addition, the daily production rate increased from $3.7 \mathrm{~m} 3 /$ day to $27.1 \mathrm{~m} 3 /$ day in the well surrounded by injectors (5-Spot)and water cut decrease from $87.9 \%$ to $45.8 \%$.[9]

Falcone \& Krumnne found out that its preferred to inject ASP once in order to stimulate their effect, reduce the injection time and in turn the cost. [10]
A laboratory study was conducted, showing that the oil recovery increased to $30 \%$ of OOIP and water cut decrease from $98 \%$ to $50 \%$ while in case of injecting $20 \%$ of PV with ASP that contains $1 \%$ Sulfonate oil, the recovery can increase to $20 \%$ of OOIP. [11]

Mahendra carried out extensive lab test on cores at (RFD) institute to evaluate ASP in Ferag field. Results showed that oil recovery increase $18 \%$ of OOIP and according to these results; a pilot test of 5 spot patterns was conducted injecting $20 \%$ PV of (1.5\% wt alkaline, 0.2 wt\% surfactant, and 800 PPM polymer). [12]

Cheng \& Denum mentioned that increase the viscosity of injected ASP solution can be used in heterogeneous formation. [13]

Tong, Zhegshin and rang concluded that the residual oil displacement using ASP is due to low IFT and emulsion. The unmovable oil turned into oil and water emulsion due to the strength of shear stress and turned into movable oil following within the ASP solution. [14]

According to P. Dowling and M.J.Pitts, the geological reserve in tanner field, due to ASP injection is composed of ( $1 \% \mathrm{wt}) \mathrm{NaOH},(0.1 \% \mathrm{wt})$ (ORS-41HF) and $1000 \mathrm{ppm}$ of polymer (AlcoFlood). There were an increasing of oil production equally $10 \%$ of OOIP. [15]

In an industrial experiment to inject the ASP in the central part of the field Daqing Xing 2 area was injected ASP solution increased by $20 \%$ PV and appeared to respond oil displacement in 19 producing wells. The oil recovery increased from 25 ton/day to 148 ton/day, and water cut decreased from $96.3 \%$ to 69.9\%. [16]

M.Delshad evaluated that the oil recovery increased by $24 \%$ of OOIP in Karmany field after mini injecting of ASP. However, Alkaline is consumed due to undesirable reactions with Calcium and other cations as well as cationic exchange with clay. [17]

Vargo pointed out that ASP injection in Cambridge field was successful, since the final oil production increased to $143,000 \mathrm{bbl}$ with cost of $2.24 \$ / \mathrm{bbl}$, where mobility control is essential for the success of the project. In addition, detailed study of reservoir and lab study of liquid impress the probability of Success. [18]

\section{Materials and Methods}

Before beginning in the Displacement operations, the following Steps must be done as the following:

Firstly: Preparation of rock sample that physically simulate the produced formation in the studies field

The sample was prepared in the following stages:

1- Sieving the sample components individually (Marble, Silica flour) by using A vibratory sieves Instrument which result in homogenous diameter of the grains. 
The used Sieve openings diameters are $(63 \mu \mathrm{M}-75$ $\mu \mathrm{M}-150 \mu \mathrm{M}-180 \mu \mathrm{M}-425 \mu \mathrm{M})$.

2- Selection of the proposed groups for Studying: the following group was suggested to study as shown in the following tables:

Table 2 : Suggested studying Groups

\begin{tabular}{|c|c|c|}
\hline $\begin{array}{c}\text { Primary } \\
\text { Component }\end{array}$ & \multirow[t]{2}{*}{$\begin{array}{c}\mu \mathrm{M} 63<(\text { Marble })<\mu \mathrm{M} 150 \\
\mu \mathrm{M} 63<(\text { Silica floor })<\mu \mathrm{M} 150\end{array}$} & \multirow[t]{2}{*}{$\begin{array}{l}\text { First } \\
\text { Group }\end{array}$} \\
\hline $\begin{array}{l}\text { Secondary } \\
\text { Component }\end{array}$ & & \\
\hline $\begin{array}{c}\text { Primary } \\
\text { Component }\end{array}$ & \multirow{2}{*}{$\begin{array}{c}63 \mu \mathrm{M}<(\text { Marble })<\mu \mathrm{M} 150 \\
\mu \mathrm{M} 150<\text { (Silica } \\
\text { floor })<\mu \mathrm{M} 425\end{array}$} & \multirow[t]{2}{*}{$\begin{array}{l}\text { Second } \\
\text { Group }\end{array}$} \\
\hline $\begin{array}{l}\text { Secondary } \\
\text { Component }\end{array}$ & & \\
\hline $\begin{array}{c}\text { Primary } \\
\text { Component }\end{array}$ & \multirow{2}{*}{$\begin{array}{c}\mu \mathrm{M} 63<(\text { Marble })<\mu \mathrm{M} 150 \\
\mu \mathrm{M} 150<(\text { Silica } \\
\text { floor })<\mu \mathrm{M} 180\end{array}$} & \multirow[t]{2}{*}{$\begin{array}{l}\text { Third } \\
\text { Group }\end{array}$} \\
\hline $\begin{array}{l}\text { Secondary } \\
\text { Component }\end{array}$ & & \\
\hline $\begin{array}{c}\text { Primary } \\
\text { Component }\end{array}$ & \multirow[t]{2}{*}{$\begin{array}{l}\mu \mathrm{M} 63<(\text { Marble })<\mu \mathrm{M} 75 \\
\mu \mathrm{M} 75<(\text { Marble })<\mu \mathrm{M} 150\end{array}$} & \multirow[t]{2}{*}{$\begin{array}{l}\text { Fourth } \\
\text { Group }\end{array}$} \\
\hline $\begin{array}{l}\text { Secondary } \\
\text { Component }\end{array}$ & & \\
\hline $\begin{array}{c}\text { Primary } \\
\text { Component }\end{array}$ & \multirow{2}{*}{$\begin{array}{c}\mu \mathrm{M} 63<(\text { Marble })<\mu \mathrm{M} 150 \\
\mu \mathrm{M} 150<(\text { Silica floor } \\
)<\mu \mathrm{M} 425\end{array}$} & \multirow{2}{*}{$\begin{array}{l}\text { Fifth } \\
\text { Group }\end{array}$} \\
\hline $\begin{array}{l}\text { Secondary } \\
\text { Component }\end{array}$ & & \\
\hline $\begin{array}{c}\text { Primary } \\
\text { Component }\end{array}$ & \multirow[t]{2}{*}{$\begin{array}{c}\mu \mathrm{M} 63>(\text { Marble }) \\
\mu \mathrm{M} 63<\text { (Silica floor })<\mu \mathrm{M} 150\end{array}$} & \multirow[t]{2}{*}{$\begin{array}{l}\text { Sixth } \\
\text { Group }\end{array}$} \\
\hline $\begin{array}{l}\text { Secondary } \\
\text { Component }\end{array}$ & & \\
\hline $\begin{array}{c}\text { Primary } \\
\text { Component }\end{array}$ & \multirow[t]{2}{*}{$\begin{array}{l}\mu \mathrm{M} 63<(\text { Marble })<\mu \mathrm{M} 150 \\
\mu \mathrm{M} 150<(\text { Marble })<\mu \mathrm{M} 180\end{array}$} & \multirow[t]{2}{*}{$\begin{array}{l}\text { Seventh } \\
\text { Group }\end{array}$} \\
\hline $\begin{array}{l}\text { Secondary } \\
\text { Component }\end{array}$ & & \\
\hline $\begin{array}{c}\text { Primary } \\
\text { Component }\end{array}$ & \multirow[t]{2}{*}{$\begin{array}{l}63 \mu \mathrm{M}<(\text { Marble })<\mu \mathrm{M} 150 \\
\mu \mathrm{M} 150<(\text { Marble })<\mu \mathrm{M} 425\end{array}$} & \multirow[t]{2}{*}{$\begin{array}{l}\text { Eighth } \\
\text { Group }\end{array}$} \\
\hline $\begin{array}{l}\text { Secondary } \\
\text { Component }\end{array}$ & & \\
\hline $\begin{array}{c}\text { Primary } \\
\text { Component }\end{array}$ & \multirow[t]{2}{*}{$\begin{array}{c}\mu \mathrm{M} 63<(\text { Marble })<\mu \mathrm{M} 75 \\
\mu \mathrm{M} 75<(\text { Silica floor })<\mu \mathrm{M} 150\end{array}$} & \multirow{2}{*}{$\begin{array}{l}\text { Ninth } \\
\text { Group }\end{array}$} \\
\hline $\begin{array}{l}\text { Secondary } \\
\text { Component }\end{array}$ & & \\
\hline $\begin{array}{c}\text { Primary } \\
\text { Component }\end{array}$ & \multirow[t]{2}{*}{$\begin{array}{l}\mu \mathrm{M} 75<(\text { Marble })<\mu \mathrm{M} 150 \\
\mu \mathrm{M} 63<(\text { Marble })<\mu \mathrm{M} 75\end{array}$} & \multirow{2}{*}{$\begin{array}{l}\text { Tenth } \\
\text { Group }\end{array}$} \\
\hline $\begin{array}{l}\text { Secondary } \\
\text { Component }\end{array}$ & & \\
\hline
\end{tabular}

3- Preparing from each group several mixtures with different percentages from Primary and secondary component as shown in the following table:

Table 3 : Weight Percentages for Primary and secondary components used in the preparation of each group

\begin{tabular}{|c|c|c|}
\hline $\begin{array}{c}\text { Mixture } \\
\text { number }\end{array}$ & $\begin{array}{c}\text { Secondary } \\
\text { component } \\
\text { Percentage (\%wt) }\end{array}$ & $\begin{array}{c}\text { Primary } \\
\text { component } \\
\text { Percentage (\%wt) }\end{array}$ \\
\hline 1 & 0 & 100 \\
\hline 2 & 5 & 95 \\
\hline 3 & 10 & 90 \\
\hline 4 & 20 & 80 \\
\hline 5 & 30 & 70 \\
\hline 6 & 50 & 50 \\
\hline
\end{tabular}

4- The mixing is performed well and in the same duration for all mixtures that mentioned in the previous table, after that stuffing each mixture into a metal cylindrical model dimensions' cm (75 X 2.54) made of stainless steel and is equipped with refineries and valves at the inlet and outlet.

5- The stuffing process is performed regularly in terms of mechanical and the time of rock grains stacking process.

6- After the ending of stuffing process of the model, the permeability of each mixture in each group is measured and this sequence of stages is performed in all prepared mixtures with different percentages for each group and the rest of the other groups as mentioned in the table (2).

7- After finishing of the permeability measurements of the permeability for all group mixture, the graphical relationship between absolute permeability gas $(\mathrm{Kg})$ and percentage weight of secondary component that was added to primary component in the studying group and as shown in the table (3)

8- From the intersection of the average permeability value for Jreebi formation that produced in DERO field which is $89.66 \mathrm{~m} . \mathrm{D}$ with drawing graphical guide and by dropping it on the axis (percentage weight of secondary component that was added to primary component), we can determine the optimum percentage for each of primary and secondary components for getting a sample have compatible or simulate permeability of the produced formation from field under studying.

9- The experiments performed in all mentioned groups which each mixture prepared with percentages according to table(3), also, the permeability was measured with drawing of a graphic relationship mentioned and shows from all experiments the two groups (fourth and nine) gave graphical guide compatible with the average permeability value for Jreebi formation that produced in DERO field, and the validation of the fourth group in the study was performed because of primary and secondary components from the marble which the Marble is metamorphic carbonic rock consists mainly from calcite grains and in some cases from dolomite grains. This marble is compatible with the produced rock structure from the DERO field.

Table 4: Results of permeability measurement of the mixtures prepared in different percentages for the fourth group

\begin{tabular}{|c|c|c|c|c|c|}
\hline $\begin{array}{c}\mathrm{P} \\
\text { (atm) }\end{array}$ & $\begin{array}{c}\mathrm{Qg} \\
(\mathrm{cm} 3 / \mathrm{Sec})\end{array}$ & $\begin{array}{c}\mathrm{T} \\
(\mathrm{oC})\end{array}$ & $\begin{array}{c}\mu \mathrm{g} \\
(\mathrm{C} . \mathrm{P})\end{array}$ & $\begin{array}{c}\mathrm{Kg} \\
(\mathrm{m} . \mathrm{D})\end{array}$ & $\begin{array}{c}\text { Mixture } \\
\text { number }\end{array}$ \\
\hline 6.329 & 1.497 & 25.5 & 0.01815 & 63.58 & 1 \\
\hline 6.329 & 1.739 & 25.5 & 0.01815 & 73.85 & 2 \\
\hline 6.329 & 2.092 & 26 & 0.01817 & 88.9 & 3 \\
\hline 6.329 & 2.638 & 21 & 0.01795 & 110.8 & 4 \\
\hline 6.329 & 3.225 & 26.5 & 0.0182 & 137.35 & 5 \\
\hline 6.329 & 4.366 & 24 & 0.0181 & 184.92 & 6 \\
\hline
\end{tabular}

The graphical representation of the result is shown in the following figure 


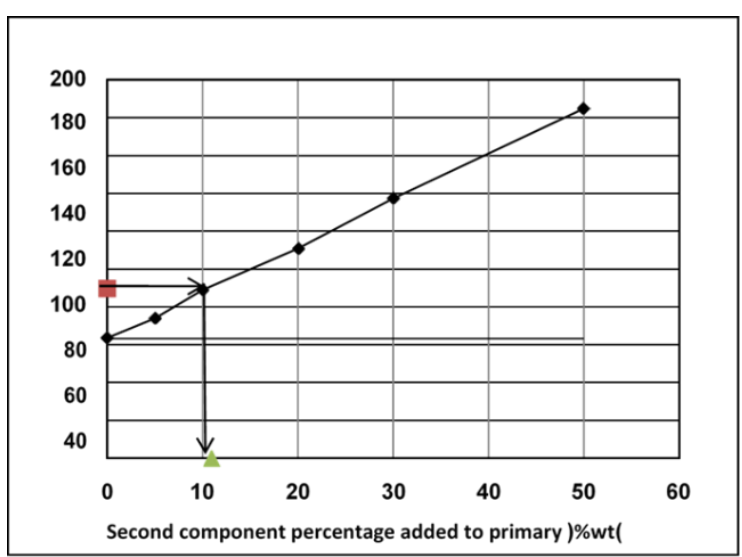

Figure 1: Absolute permeability change $(\mathrm{kg})$ and relationship with (Second component percentage that was added to primary component \%wt) for the fourth Group

From the intersection of the average permeability value for Produced Jreebi formation of DERO field (89.66 m.D) with Graphical guide and by dropping on the $X$ we found the optimum percentage for each primary and secondary components (that Achieve a rock sample has a permeability compatible with average permeability of mentioned formation) is:

- Percentage of primary component: $89 \%$ wt $\mu \mathrm{M} 63<$ (Marble) < $\mu \mathrm{M} 75$

- Percentage of secondary component: $11 \%$ wt $\mu \mathrm{M}$ $75<$ (Marble) $<\mu \mathrm{M} 150$

\section{Secondly: Preparation of rock sample for} displacement operation:

Include the following procedure:

1- Emptying the model form the air: by placing the model vertically as shown in the following figure:

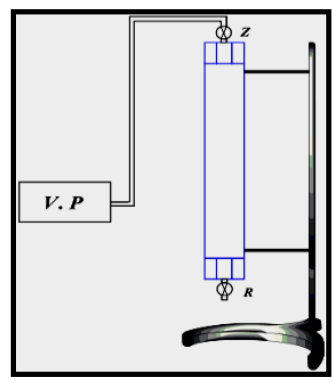

Figure 2: Scheme shows the emptiness of the model from the air

The emptying operation of the model from the air is done by the following procedures :

Connect the upper valve (Z) with Vacuum Pump V.P Close the Valve (R) - Open the valve (Z)- run the vacuum pump at least for one hour - after ending of vacuum operation close valve (Z)

2- Saturate the model by kerosene : Saturation of the model by kerosene as shown in the following figure.

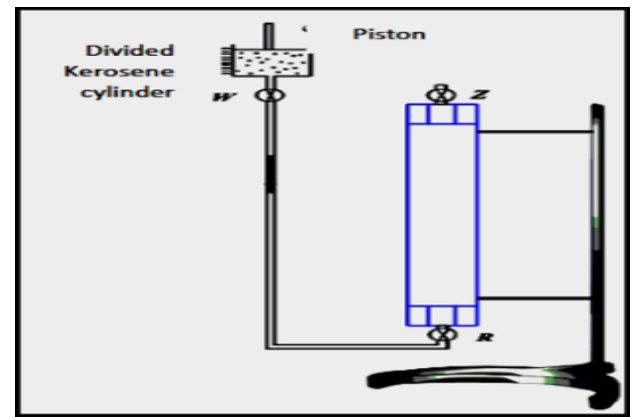

Figure 3: Scheme shows the saturation operation of the model by kerosene

The Saturation operation of model by kerosene according to the following procedures

- The model is connected with graduated vessel that contain kerosene.

- The valve (W) open until arrival of the kerosene to pre closed vale (R).

- Opens the valve $(R)$ to expel air from the line linking valves $W$ and $R$ until exit of kerosene, then closes the valve $R$ and connects with the model from the bottom.

- Initial reading taken on the graduated vessel of kerosene (V1), then opens the valve (Z) and valve R. To start the entrance of the kerosene to the model.

- At the exit of the first drop of kerosene from the valve $(Z)$ closed valves $(Z, W, R)$, and reads the volume of kerosene on the graduated vessel again(V2).

- The difference between the two readings represent the kerosene volume which entered the model dv1.

3- Drying the model from the Kerosene: This process is done according to the following stages:

- Vacuum pump connects to the model via the valve $\mathrm{R}$ from the bottom to withdraw the kerosene from the model. (Discharge duration at least an hour)

- Then, the model is placed in an oven at temperature $90^{\circ} \mathrm{C}$ for 24 hours to dry the model from the kerosene.

4- Saturation of the model by water to achieve connate water : this done by installing the model in the instrument as shown in figure (4) to be fully saturated with water which is injected volume of water which is equivalent to three times volume dv1 


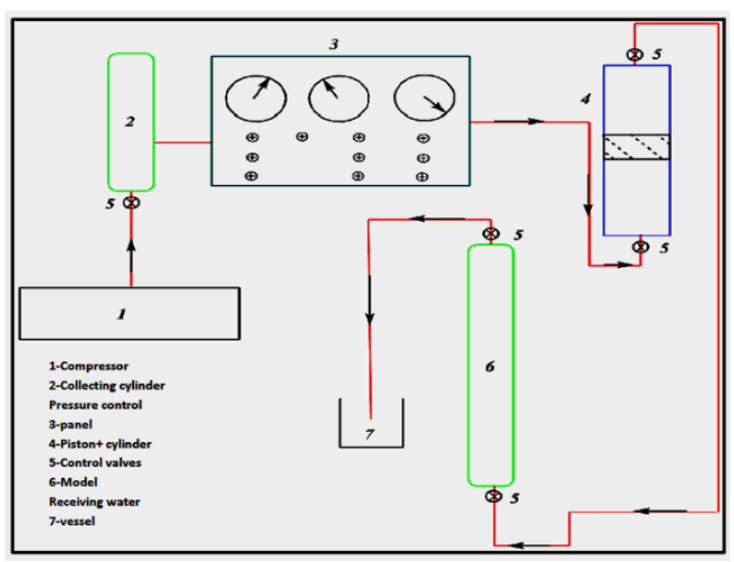

Figure 4:Instrument scheme used to saturate the model by water and washing the model by kerosene

5- Displacement of free water from the model: this done according to the following procedures:

- Keep the model vertically and connects with the vacuum pump from the bottom of valve $R$ until stopping the flow of the water.

- The model is then placed in the drying oven $90^{\circ} \mathrm{c}$ for three days until the exit of the remaining amounts of free water from it.

6- Saturation of the model with kerosene another time: the previous steps mentioned in number (2) is repeated and the volume of $d v 2$ which represent the difference between the first reading of the volume of kerosene on the graduated vessel and the final reading. The difference between the two volumes $d v 1$ and $d v 2$ represents the volume of connate water in the model. While the volume dv2 represents the volume of effective pores in the model which will saturate with the oil

\section{Results and discussion:}

- model Volume V=F.L=5.064 $\times 75=379.8 \mathrm{~cm}^{3}$

- Kerosene Volume that entered model dv1 at the first time of model saturating by Kerosene is $129.4 \mathrm{~cm}^{3}$. its equal the total Pore Volume of the model.

- Kerosene Volume that entered model dv2 at the second time of model saturating by Kerosene is $112.8 \mathrm{~cm}^{3}$. its equal oil saturated Pore Volume of the model .

- If we considered : Kerosene Volume that entered model dv2 is equal Pore Volume that's mean the model Porosity is $29.6 \%$.

- The Average Porosity of DERO Field is \% 27.43 .

- By comparison: we will find a difference equally $2.17 \%$. this difference because Kerosene Volume dv2 is not exactly equal oil saturated Pore Volume of the model because the rock Particles of the model will saturated by a part of Kerosene.

- Connect water volume in the model is :

$$
\begin{aligned}
& \mathrm{V}_{\mathrm{w}}=\mathrm{dv} 1-\mathrm{dv} 2 \\
& \mathrm{~V}_{\mathrm{w}}=129.4-112.8=16.6 \mathrm{~cm}^{3}
\end{aligned}
$$

\section{7- Formation oil sample preparation :}

It is known that the formation oil has certain density, viscosity and strong surface tension. Therefore, during laboratory experiments and displacement operations Dead oil taken from the field cannot be used, but an oil sample that achieves the same specifications of formation oil must be prepared.

This sample is prepared by following these steps:

- Kerosene is added to the oil (DERO oil field) and that for the following volumes: $20-40-60-80-100 \%$ vol

- After mixing process of each sample the following indexes is measured at a temperature of the field studied :

- Interfacial tension (IFT) between mixture (kerosene + Oil) and water.

- Density (d).

- Surface tension $(\sigma)$.

- Oil viscosity $\left(\mu_{o}\right)$.

- Draw a graphic relationship between the viscosity of each sample and the volumetric percentage of kerosene added $C_{k}$.

- From the intersection of the value of the field oil viscosity which is studied at stratified conditions with graphic evidence. The projection on the axis of the proportion of the added kerosene, determine the ideal ratio of kerosene that must be added to the oil viscosity to achieve the consent of the of formation oil viscosity. Depending on the ratio reached kerosene oil is added and mixed well with it, and so we have prepared the model of oil corresponding to formation oil in terms of viscosity. Measurement results are shown in the following table :

Table 5: the results of prepared models measurement with kerosene added to the oil at different volumetric

\begin{tabular}{|c|c|c|c|c|c|c|c|}
\hline $\begin{array}{c}\mathrm{C}_{\mathrm{k}} \\
\text { \%vol }\end{array}$ & 0 & 20 & 40 & 60 & 80 & 100 & $\underset{s}{\text { remark }}$ \\
\hline $\begin{array}{c}\sigma \\
\text { (m.N } \\
/ \mathrm{M})\end{array}$ & 27.5 & 26.8 & 26.1 & 25.6 & 25.0 & 24.6 & \multirow{4}{*}{$\begin{array}{c}\mathrm{T}=33^{\circ} \mathrm{C} \\
\text { Tesiom } \\
\text { ete: } \\
\text { Kruss } \\
\text { K10 } \\
\\
\text { Viscom } \\
\text { ete: } \\
\text { FUNGIL } \\
\text { AB }\end{array}$} \\
\hline $\begin{array}{c}\mu_{o} \\
\text { (C.P) }\end{array}$ & 11.17 & 4.461 & 2.604 & 1.787 & 1.21 & 1.05 & \\
\hline $\begin{array}{c}d \\
(\mathrm{~g} / \mathrm{cm} \\
\left.{ }_{3}\right)\end{array}$ & $\begin{array}{c}0.862 \\
5\end{array}$ & $\begin{array}{c}0.843 \\
8\end{array}$ & $\begin{array}{c}0.827 \\
1\end{array}$ & 0.811 & 0.794 & 0.775 & \\
\hline $\begin{array}{l}\text { IFT } \\
\text { (m.N } \\
\text { /M) } \\
\end{array}$ & 12.7 & 13.0 & 13.8 & 14.6 & 15.5 & 38.5 & \\
\hline
\end{tabular}
percentage of Kerosene $C_{k}$

Note: For the results of the viscosity of dynamic Entries in the previous table has been reached by measuring kinematic viscosity first using a device (FUNGILAB) which is provided with water bath, where the time required for the passage of each sample mixture (kerosene + Oil) was measured over Ostphald existing scale within the device. The results of measurements of the device are shown in the following table: 


\begin{tabular}{|c|c|c|c|c|c|c|c|}
\hline $\begin{array}{c}C_{k} \\
\% v \\
\text { ol }\end{array}$ & $\begin{array}{c}\mathrm{T} \\
\text { (sec) }\end{array}$ & C & $\begin{array}{c}v \\
(\mathrm{~cm} 2 / \mathrm{se} \\
\text { c) }\end{array}$ & $\begin{array}{c}d \\
(\mathrm{~g} / \mathrm{cm} \\
3)\end{array}$ & $\underset{\text { (C.P) }}{\mu}$ & $\begin{array}{c}\mathrm{T} \\
\text { (sec) }\end{array}$ & remarks \\
\hline 0 & 248 & 0.052279 & 12.965 & 0.862 & 11.17 & 248 & \multirow{4}{*}{$\begin{array}{l}T=33^{\circ} \mathrm{C} \\
\text { C: device } \\
\text { constant }\end{array}$} \\
\hline 20 & 526 & 0.010062 & 5.292 & 0.843 & 4.461 & 526 & \\
\hline 40 & 313 & 0.010062 & 3.149 & 0.827 & 2.604 & 313 & \\
\hline 60 & 219 & 0.010062 & 2.203 & 0.811 & 1.787 & 219 & \\
\hline
\end{tabular}

Graphical representation of the relationship of the oil viscosity change by adding kerosene shown as follows

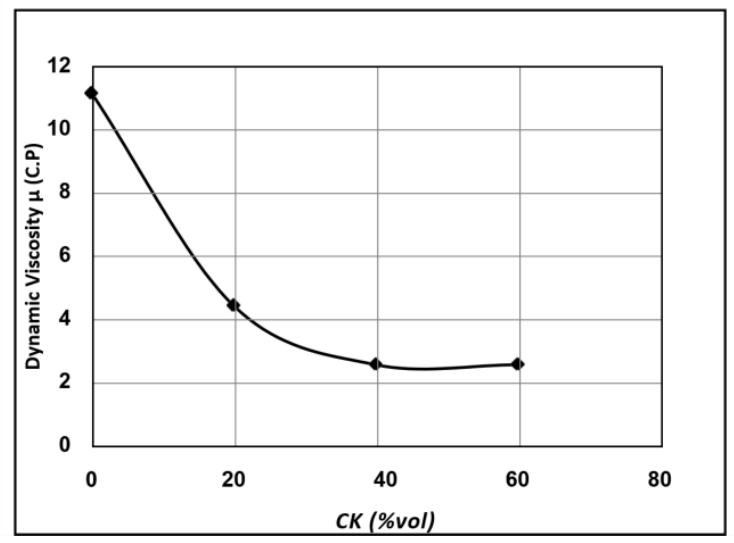

Figure 5: change of dynamic viscosity of the oil with the volumetric ratio of kerosene added $C_{k}$

\section{Results and discussion:}

- From the intersection of oil formation viscosity of the studied field8 which equal to 4.5 C.P it found that the optimum volume of added kerosene is to $C_{k}=19.5 \%$ vol

- The study depends on the method of adding the kerosene to the oil instead of other methods in preparation of formation oil model as mentioned previously, where the added amount of kerosene to prepare the model was significantly little $(19.5 \% \mathrm{vol})$, in addition to the interfacial tension (oil/water) did not change extremely as shown in the table, where the values of (IFT) as the following:

IFT $\left(C_{K}=0 \%\right.$ vol $)=12.7 \mathrm{~m} . \mathrm{N} / \mathrm{M}$. IFT $\left(C_{K}=20 \%\right.$ vol $)=$ $13 \mathrm{~m} . \mathrm{N} / \mathrm{M}$.

\section{8- Saturation of the model by the oil :}

After the preparation of the oil formation sample, the saturation process of model by oil is done by using the pump that shown in the following figure:
Figure 6 :Scheme shows model saturation instrument

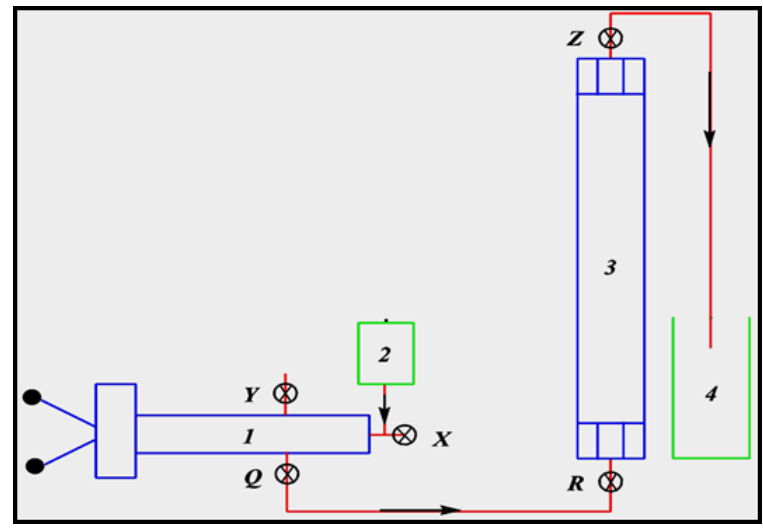

by the oil

Q: oil pump connection valve with model.

$\mathrm{Y}$ : oil pump connection valve with station

1: Oil Pump.

$X:$ Pump plunger fill valve

2: vessel connected pump plunger.

$\mathrm{R}$ : model bottom valve.

3: The model

Z: model upper valve

4: Vessel receiving the oil and displaced water.

\section{9- Sweeping the model by the water (Water Flooding) :}

Water is injected into the model until reach about 250\% PV with same injection rate and with the same injection conditions when injected ASP solution later. The effectiveness of the water injection is determined through the stoppage of the oil form the model outlet. After that the model will be ready for injection process of ASP solution in order to extract the remaining oil quantities using effectiveness of ASP solution components.

\section{Thirdly: Displacement Operations}

The following figure shows Displacement and injection station schematic that used in the experiments :

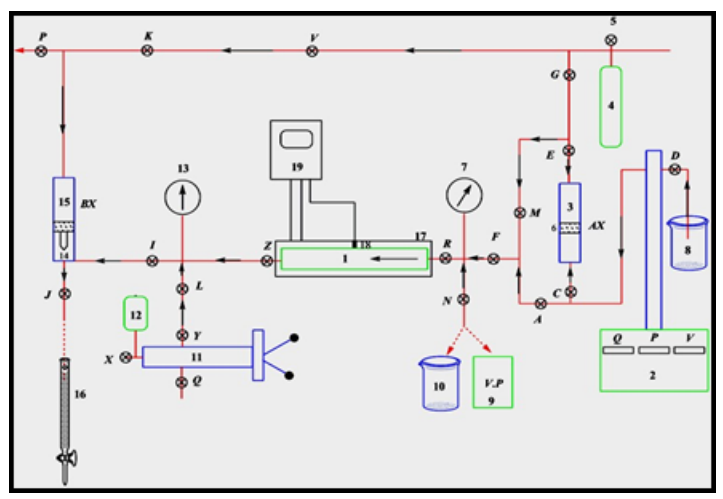

Figure 7:Displacement and injection station schematic 


\section{Plant components :}

1. rock model made of stainless steel metal casing

2. Injection pump: Piston pump through which the pressure and the rate of injection is controlled automatically.

3. Cylinder active ingredient $A X$ and contains $a$ piston inside separates between the active substance above (ASP injection solution) and liquid displacement below.

4. Air cylinder.

5. pressure regulating valve

6. Piston cylinder of the active substance.

7. Inlet pressure gauge of the model.

8. Displacement fluid.

9. unloading pump

10. Drainage pot.

11. Piston pump to saturate model with oil.

12. Oil holder.

13. Outlet pressure gauge.

14. Needle valve.

15. BX cylinder.

16. Graduated burette in millimeter parts

17. Model Temperature raiser device.

18. Temperature sensor.

19. Model temperature controller.

20. Valves: D-C-A-G-E-M-F-N-R-Z-L-I-Y-Q-X-J-K-

\section{Work Mechanism of displacement plant:}

1- Put model in place within the temperature raising device.

2- Connects valves $(R, Z)$ with the model.

3- Adjust the model on temperature $\left(33^{\circ} \mathrm{C}\right)$ (degrees studied field temperature) using a device connected to the electric heater within the temperature raising device.

4- $\quad$ Fill the needle valve cylinder (BX) with oil.

5- Open the valves $(\mathrm{V}, \mathrm{K})$ to increase the pressure until the air cylinder pressure (4).

6- Defy the pressure inside the cylinder (BX) until it becomes equal to the formation pressure (45 atm) to open valve $(P)$ to vent excess air (reading on the grand scale of the left-wing pressure).

7- Fill the cylinder (AX) with ASP solution and displacing water (ASP solution higher piston and water down the piston).

8- Close the valve (N) and raise the pressure until the desired pressure.

9- Take reading on the pump (reading V1)

10- Open the injection valve $(R)$ for the ASP solution where it moves through valves ( $E, M, F$ begin, $R$ ) Open (valve $A$ is closed).
11- Oil moves out of the valve (J) which opens and receives through graduated tube.

12- When the solution injection stops at the desired volume,

13- Take reading (V2) and close valve R.

14- Close the valve (M) and opens the valve (A) until the water get out of the valve $(N)$ that opens.

15- Close the valve $(\mathrm{N})$ relieved the pressure pump up the value (45atm) and the reading taken (V1) which is (read start mass displacement injection). Then opens the valve $(R)$.

16- After the end of injection of displacing water, close valve $\mathrm{R}$, take reading $\mathrm{V} 2$ on the pump at the end of injection, where (V2-V1) is the volume of water injected (liquid displacement).

17- Repeat water injection at different volumes until total fluid injected is equal (250\%) of the size of the pore spaces.

18- . At the end of each injection stage\% PV (15-3050-100-150-200-250) is measured by the size of each of the oil and water resulting from the displacement and leaving the valve $(J)$ through graduated tube with millimeters scale.

\section{List of symbols:}

- $\mathrm{V}_{\mathrm{pv}}$ : ratio of injected liquid volume to pore volume (\%) $V_{A}$ : the relative amount of the injected liquid $(\mathrm{ml})$.

- $\mathrm{V}_{\mathrm{x}}$ : volume of liquid injected at each stage $(\mathrm{ml})$.

- $\Delta v$ : volume of liquid injected into the single-stage $\mathrm{V} 2-\mathrm{V} 1(\mathrm{ml}) . \mathrm{V}_{\mathrm{T}}$ : cumulative volume of liquid injected (ml).

- $\mathrm{V}_{\mathrm{o}}$ : cumulative volume of oil produced $(\mathrm{ml})$

- $\mathrm{V}_{\mathrm{w}}$ : cumulative volume of water produced with oil (ml). O.D.F: Oil Displacement factor (\%).

- W: the proportion of water in the liquid product (oil+ water) $\mathrm{W} \%=\mathrm{V}_{\mathrm{w}} / \mathrm{V}_{\mathrm{T}} .100$ R.a: suggested factor (Recoverability) represents the ratio between the cumulative volume of oil produced in each injection to the cumulative volume of fluid injected at the same stage phase $(\mathrm{ml} / \mathrm{ml}): \mathrm{Ra}=\mathrm{V}_{\mathrm{O}} / \mathrm{V}_{\mathrm{T}}$.

- P1: inlet pressure (45 atm), which is equal to the average formation pressure of the DERO field.

- P2: model outlet pressure (42 atm), which is equal to the average production wells bottom pressure.

- Q: liquid injection rate in the model $(65.38 \mathrm{ml} /$ hour) which is constant so that it corresponds to the inlet and outlet pressure in the model.

- Oil PV: the size of the model pore spaces saturated with oil which is equal to $\mathrm{cm}^{3}$.

The results of displacement mechanism are summarized in the following tables and figures: 
Table 7: Results of the chemical injection process $($ ASP-P) at ASP injection ratio $=15 \% \mathrm{P}$

\begin{tabular}{|l|l|l|l|l|l|l|l|l|l|}
\hline $\begin{array}{l}\mathbf{V}_{\mathbf{p v}} \\
(\%)\end{array}$ & $\begin{array}{l}\mathbf{V}_{\mathbf{A}} \\
(\mathbf{m l})\end{array}$ & $\begin{array}{l}\mathbf{V}_{\mathbf{x}} \\
(\mathbf{m l})\end{array}$ & $\begin{array}{l}\mathbf{\Delta v} \\
(\mathbf{m l})\end{array}$ & $\begin{array}{l}\mathbf{V}_{\mathbf{T}} \\
(\mathbf{m l})\end{array}$ & $\begin{array}{l}\mathbf{V}_{\mathbf{o}} \\
(\mathbf{m l})\end{array}$ & $\begin{array}{l}\mathbf{V}_{\mathbf{w}} \\
(\mathbf{m l})\end{array}$ & $\begin{array}{l}\text { O.D.F } \\
(\%)\end{array}$ & $\begin{array}{l}\mathbf{W} \\
(\%)\end{array}$ & R.a \\
\hline $\begin{array}{l}\mathbf{1 5} \\
\text { ASP }\end{array}$ & 16.92 & 16.92 & 16.92 & 16.9 & 15.2 & 1.7 & 13.5 & 10 & 0.89 \\
\hline $\mathbf{3 0}$ & 33.84 & 16.92 & 16.92 & 33.8 & 16.9 & 16.9 & 15.0 & 50 & 0.5 \\
\hline $\mathbf{5 0}$ & 56.4 & 22.56 & 22.56 & 56.4 & 17.4 & 39 & 15.4 & 69.1 & 0.30 \\
\hline $\mathbf{1 0 0}$ & 112.8 & 56.4 & 56.4 & 112.8 & 17.8 & 95 & 15.8 & 84.2 & 0.15 \\
\hline $\mathbf{1 5 0}$ & 169.2 & 56.4 & 56.4 & 169.2 & 18.0 & 151.2 & 16.0 & 89.3 & 0.10 \\
\hline $\mathbf{2 0 0}$ & 225.6 & 56.4 & 56.4 & 225.6 & 18.6 & 207 & 16.5 & 91.7 & 0.08 \\
\hline $\mathbf{2 5 0}$ & 282 & 56.4 & 56.4 & 282 & 19 & 263 & 16.8 & 93.2 & 0.06 \\
\hline
\end{tabular}

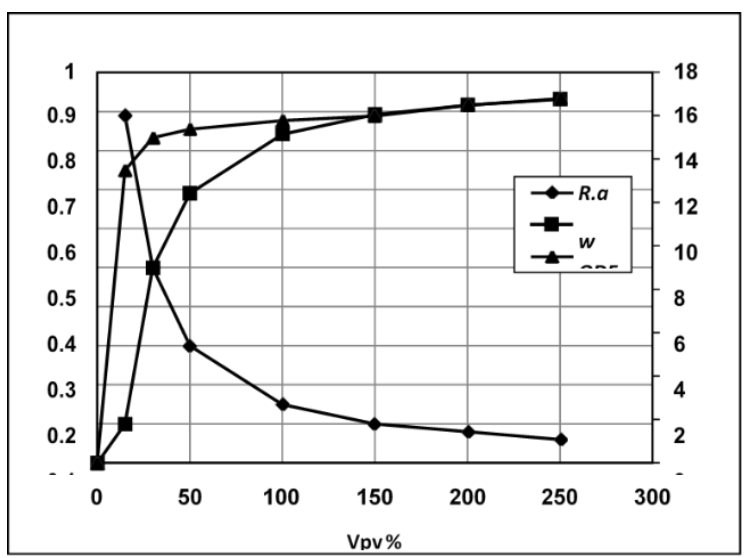

Figure 8: change each Of O.D.F, R.a and W by relationship with $\mathrm{V}_{\mathrm{PV}} \%$ at $\mathrm{ASP}$ injection ratio $=15 \% \mathrm{PV}$

Table 9:Results of the chemical injection process (ASP$\mathrm{P})$ at ASP injection ratio $=50 \% \mathrm{PV}$

\begin{tabular}{|c|c|c|c|c|c|c|c|c|c|}
\hline $\begin{array}{l}V_{p v} \\
(\%)\end{array}$ & $\begin{array}{c}\mathrm{V}_{\mathrm{A}} \\
(\mathrm{ml})\end{array}$ & $\begin{array}{l}V_{x} \\
\text { (ml) }\end{array}$ & $\begin{array}{c}\Delta v \\
(\mathrm{ml})\end{array}$ & $\begin{array}{l}V_{T} \\
(\mathrm{ml})\end{array}$ & $\begin{array}{c}V_{o} \\
\text { (ml) }\end{array}$ & $\begin{array}{c}V_{w} \\
(\mathrm{ml})\end{array}$ & $\begin{array}{c}\text { O.D. } \\
\text { F } \\
\text { (\%) }\end{array}$ & $\begin{array}{l}W \\
\text { (\%) }\end{array}$ & R.a \\
\hline \multirow{3}{*}{$\begin{array}{c}50 \\
\text { (ASP) }\end{array}$} & - & - & - & - & 16.9 & 0 & 15 & 0 & 1 \\
\hline & - & - & - & - & 29.7 & 4.1 & 26.3 & 12 & 0.87 \\
\hline & 56.4 & 56.4 & 56.4 & 56.4 & 39.5 & 16.9 & 35 & 29.9 & 0.7 \\
\hline \multirow{3}{*}{100} & \multirow{3}{*}{112.8} & 16.9 & 16.9 & 73.32 & \multirow{3}{*}{42.2} & \multirow{3}{*}{70.6} & \multirow{3}{*}{37.4} & \multirow{3}{*}{62.5} & \multirow{3}{*}{0.37} \\
\hline & & 2 & 2 & & & & & & \\
\hline & & $\begin{array}{c}39.4 \\
8\end{array}$ & $\begin{array}{c}39.4 \\
8\end{array}$ & 112.8 & & & & & \\
\hline 150 & 169.2 & 56.4 & 56.4 & 169.2 & 42.4 & 126.8 & 37.6 & 74.9 & 0.25 \\
\hline 200 & 225.6 & 56.4 & 56.4 & 225.6 & 42.7 & 182.9 & 37.9 & 81 & 0.19 \\
\hline 250 & 282 & 56.4 & 56.4 & 282 & 43 & 239 & 38.1 & 84.7 & 0.15 \\
\hline
\end{tabular}

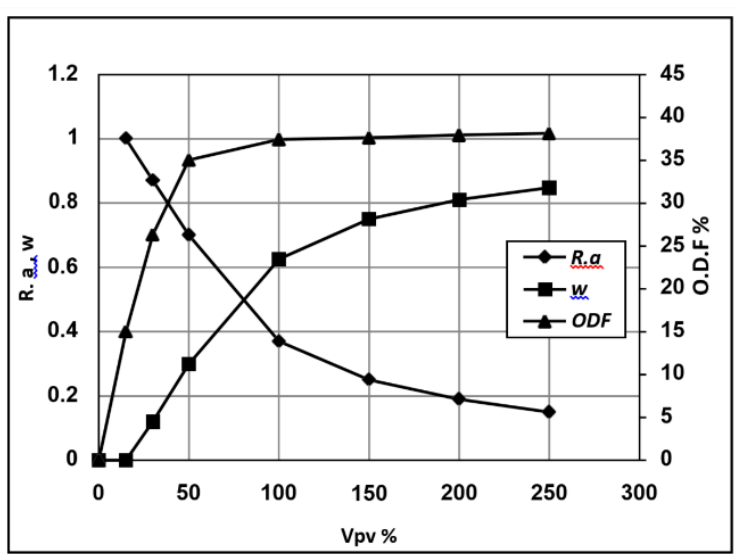

Figure 10: change each Of O.D.F, R.a and $W$ by relationship with $\mathrm{V}_{\mathrm{PV}} \%$ at $\mathrm{ASP}$ injection ratio $=50 \% \mathrm{PV}$

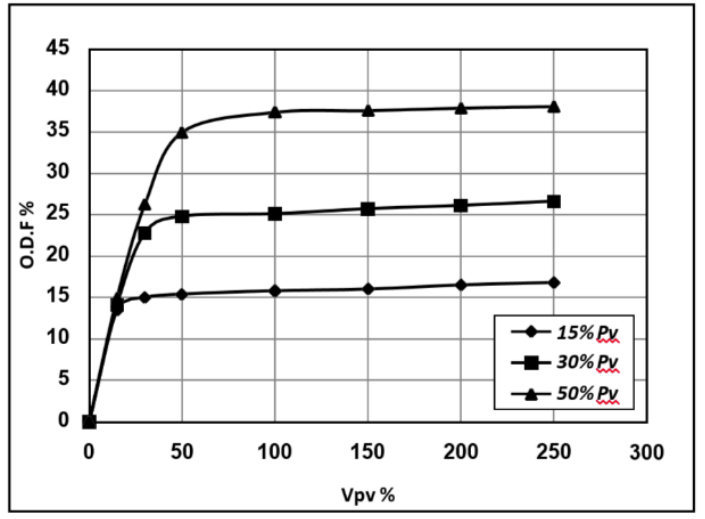

Figure 11: change Of O.D.F by relationship with $\mathrm{V}_{\mathrm{PV}} \%$ at all ASP injection ratios

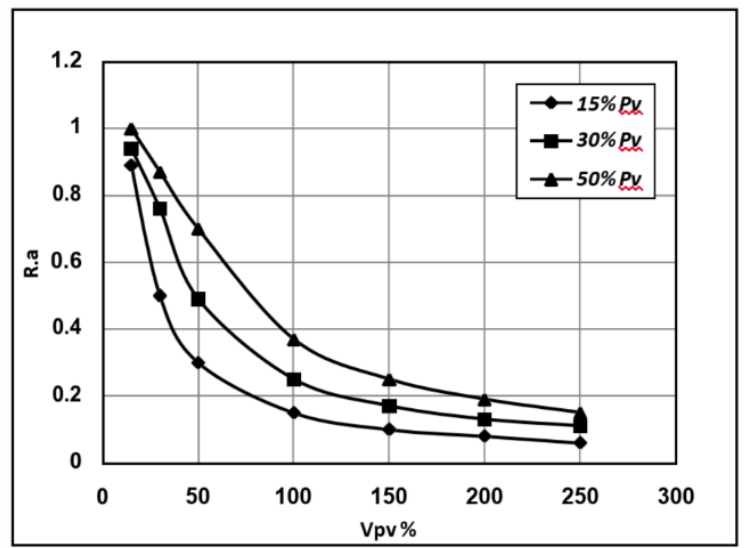

Figure 12: change Of R.a by relationship with $\mathrm{V}_{\mathrm{PV}} \%$ at all ASP injection ratios

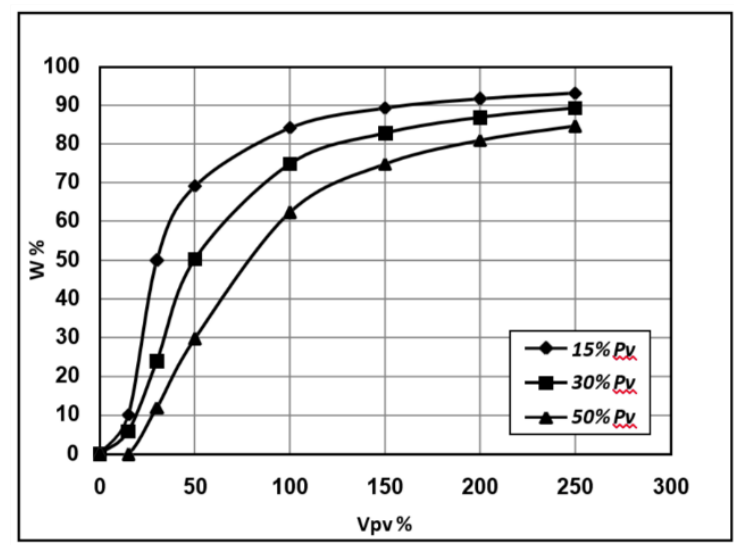

Figure 13: change of $W$ by relationship with $V_{P V} \%$ at all ASP injection ratios

\section{Results and discussion}

Before discussion of the result, it should be known that the flooding operation by ASP solution was done after a complete displacement of the model by water. In other word, the water flooding operation was done according to the same condition of the flooding plant in the field when displacing with ASP solution as in the following table 
Table 10: Results of flooding operations at all ASP injection ratios.

\begin{tabular}{|c|c|c|c|}
\hline $\begin{array}{c}\text { O.D.F(max) } \\
\%\end{array}$ & $\begin{array}{c}W(\min ) \\
\%\end{array}$ & R.a (max) & $\begin{array}{c}\text { ASP injection ratio } \\
\% P V\end{array}$ \\
\hline 16.8 & 10 & 0.89 & 15 \\
\hline 26.6 & 5.9 & 0.94 & 30 \\
\hline 38.1 & 0 & 1 & 50 \\
\hline
\end{tabular}

It observed from the result that shown in the previous tables the following:

1- Apparent increase in oil displacement factor (O.D.F) as along as with increasing the volume of injected ASP solution to pore spaces volume.

2- Reduction of the water cut with increasing the percentage of injected ASP solution to the volume of pore spaces.

3- Increasing the factor Ra with increasing the the percentage of injected ASP solution to pore spaces volume.

4- The reasons that lead to increase O.D.F, R.a and reduction of $W$ with increasing the percentage of injected ASP solution to pore spaces volume to effect the following factors :

- Reduction in the interfacial Tension between the oil and water : The reduction of the surface tension forces between the oil and water through interfacial tension reducer in the injected ASP solution that contribute to free the remaining oil in pore spaces in the model and make it more movable which results in increasing the displacement factor. In addition to that, the presence of alkali in the injection solution (ASP) also, plays this role. The increase in displacement factor through adding alkali to the injection solution (ASP) depends on the following fundamental factors, which are reductions of the interfacial tension, Emulsification of oil, wet ability alteration, in addition, the presence of the alkali work to adjust the $(\mathrm{PH})$ degree toward alkali direction which leads to reduction the adsorption of surface tension reducer within the solution on the surface of the rock grains in the model.

- Reduction of the Mobility ratio between the oil and water: The presence of polymer in the ASP solution leads to increase the water viscosity $(\mu \mathrm{w})$ and reduction of ( $\mathrm{Krw}$ ) which result in the reduction of mobility ratio between oil and water to be equal to 1 or less than 1 .

- Reduction of the Mobility ratio between the oil and water: The presence of polymer in the ASP solution leads to increase the water viscosity $(\mu \mathrm{w})$ and reduction of ( $\mathrm{Krw}$ ) which result in the reduction of mobility ratio between oil and water to be equal to 1 or less than 1 .

- Increasing the Capillary number (Nc) : which is given by thefollowing relationship: $N c=\frac{V \cdot \mu}{\sigma}$

Nc: Capillary Number.
V: Darcy Velocity.

$\mu$ : Viscosity.

$\sigma:$ Interfacial Tension.

The increasing of Capillary number leads to increase the displacement factor through reduction $(\sigma)$ or increase $(\mu)$ for the injected solution. Where results in presence of surface tension reducer and polymer in injected ASP solution to decrease $(\sigma)$, increase $(\mu)$ and therefore increasing the capillary number $(\mathrm{Nc})$ which lead to displacement of remaining oil in the model effectively.

\section{- Emulsification of oil:}

These results from the alkali reaction in the injected ASP solution with the organic acid present in the oil, which two types of emulsions formed as the following:

A- Emulsion of oil in water.

B- Emulsion of water in oil.

The form of emulsions result in reduction of the relative permeability of the water, which leads to coalescence of oil emulsion droplets to higher oil saturation, in addition leads to increase the relation permeability of the oil and increase the displacement factor.

\section{- Wettability alteration :}

Where the surface tension reducer in the injected ASP solution contributes in changing wet ability from oil wet to water wet as result of the surface electrical charges effect and Van der Waals forces on oil wet ability properties which leads to increase the produced oil volume and therefore increase the relative permeability of the oil in the model over relative permeability of water.

\section{Conclusions}

1. In respect of the laboratory, positive results that have been reached as result of this study it can adopt the ASP injection method as way to increase the oil recovery factor in DERO field.

2. We suggest applying this method on minor model (Pilot) in the studied filed and monitoring the result of these operation in the field.

3. Moreover, in case of obtain encouraging results it can be generalized this mentioned method on the entire filed.

4. In addition, this method can be applied with water injection that is currently applied in the mentioned field.

5. In addition to mentioned previously, there are oil fields have the same specifications or feasible with screening criteria of ASP injection method where they can be benefit from the results of the laboratory study of DERO field to be simulated in the application to other fields. 


\section{References}

[1] D.L.Zang, Sliu "Favorable Attributes Of AlkalineSurfactant- Polymer Combination Flooding " SPE 2006.

[2] Songwanchao,YangChengzhi"Alkaline-SurfactantPolymer Combination Flooding For Improving Recovery of The Oil" SPE 1995.

[3] YaunShiyi, Yang Hau "Effects Of Important Factors On Alkaline/Surfactant/Polymer Flooding" SPE 1998.

[4] Gao, Shutang, Li Huabin "Laboratory Investigation Of Combination Of Alkaline/Surfactant/Polymer Technology For Daging EOR" SPE 1995

[5] Yaun Shiyi, Yang Hau "Effects Of Important Factors On Alkaline/Surfactant/Polymer Flooding" SPE 1998.

[6] Gau Shut Ang, Li Huabin " Alkaline/Surfactant/Polymer Pilot Performance Of The West Central Saertu, Daqing Oil Field" SPE 1996.

[7] Songwanchao, YangChengzhi"Alkaline-SurfactantPolymer Combination Flooding For Improving Recovery of The Oil" SPE 1995.

[8] WeiWang,YonganGu"DetectionAnd Reuse Of Produced Chemicals In Alkaline/Surfactant/Polymer Floods" SPE 2003.

[9] Gau Shut Ang, Li Huabin " Alkaline/Surfactant/Polymer Pilot Performance Of The West Central Saertu, Daqing Oil Field" SPE 1996

[10] P.H.Krumrine,J.S.Falcone"Surfactant,PolymerAndAlkali ne Interactions In Chemical Flooding Processes" SPE 1983.

[11] Gao, Shutang, Li Huabin "Laboratory Investigation Of Combination of Alkaline/Surfactant/Polymer Technology For Daging EOR" SPE 1995

[12] MahendraProtap"Field Implementation Of Alkaline/Surfactant/Polymer(ASP) Flooding: Amaiden Effort In India" SPE 2004.

[13] Wang Demin, Cheng Jiecheng "An Alkaline/Surfactant/Polymer Field Test In A Reservoir With A Long Term 100 \% Water Cut" SPE 1998.

[14] Zhengshin Tong, ChengzhiYang "A Study Of Microscopic Flooding Mechanism Of ASP" SPE 1998.

[15] M.J.Pitts, P.dowling " Alkaline/Surfactant/Polymer Flood Of The Tanner Field" SPE 2006.

[16] Li Hong Fu, Liao Guangzhi " Alkaline/Surfactant/Polymer (ASP) Commercial Flooding Test In Central Xing2 Area Of Daqing Oil Field" SPE 2003.

[17] M.delshad,"Alkaline/Surfactant/Polymer Flood Predictions ForThe Karmary Oil Field" SPE 1998.

[18] JayVargo,JimTurner"Alkaline/Surfactant/Polymer Flooding Of The Cambridge Minnelusa Field" SPE 2000. 